\title{
Prospective Survey of Availability of Cadaveric Kidneys for Transplantation
}

\author{
S. L. DOMBEY, M. S. KNAPP
}

British Medical fournal, 1975, 2, 482-483

\section{Summary}

A prospective study in Nottingham hospitals, serving $\frac{3}{4}$ million population, identified 25 potential kidney donors in one year. Seventeen later died in circumstances when kidney donation would have been possible. Twelve kidneys were actually removed for transplantation out of the possible 34 .

The reasons for failure to donate kidneys were either relatives' refusal or a failure of the doctors looking after those patients to consider them as potential donors.

If all possible donors had their kidneys removed there would be sufficient available to approximately equal the numbers of patients likely to require renal transplantation.

\section{Introduction}

Renal transplantation has caused much discussion over the last few years. "News" about the inadequate number of kidney donors has frequently reached the national press. Few facts are available about the number of potential donors and the reasons why the kidneys are not being used. Crosby et al. ${ }^{1}$ after a retrospective study considered that there were likely to be sufficient kidney donors but that, "inadequate communication between the clinicians caring for potential donors and the

City Hospital, Hucknall Road, Nottingham

S. L. DOMBEY, M.B., M.R.C.P., Research Registrar (Now Registrar, Nottingham General Hospital, Nottingham)

M. S. KNAPP, M.D., M.R.C.P., Consultant Physician

surgeons working in kidney units" was responsible for the shortage of kidneys.

The availability of cadaveric kidneys, under the present law, depends on three factors: (1) the number of people dying in circumstances where their kidneys could be used for transplantation, as judged by current criteria; (2) the awareness and willingness of doctors looking after such patients to consider the possibility of kidney donation and to take appropriate action; (3) the views of relatives who are asked to give consent on behalf of their next of kin. This paper reports a prospective study carried out over one year to try to determine the relative importance of these three factors.

\section{Method}

It was decided to concentrate on patients in intensive care units, but an awareness of potential donors on the general wards was maintained. In addition neurosurgical patients were considered. There are two intensive care units in Nottingham, one associated with an accident and emergency department. One of the regional neurosurgical units is at Derby, and Nottingham patients are sometimes transferred there.

One observer (S.L.D.) visited the intensive care unit approximately twice each week to note whether there might be any potential donors. The assessment consisted in looking at the case notes of all the patients admitted to the units and following up those patients considered to be "potential" donors. No contact was made with the doctors looking after the patients, in order to avoid influencing any decisions.

The criteria used were that urine output was adequate, blood urea was normal, there was no sustained hypotension, and sudden death seemed probable or possible. Patients with systemic infection, malignancy (other than cerebral tumours), and recent abdominal surgery were excluded. This study was carried out from 1 August 1973 to 31 July 1974. Nottingham patients transferred to the neurosurgical unit at Derby were 
reviewed retrospectively at approximately three-monthly intervals. This part of the study consisted in reviewing the case notes only.

\section{Results}

Nottingham hospitals serve a population of 731400 . There were 594 admissions to the intensive care units and 30 patients identified who were transferred to the neurosurgical units from Nottingham. Twenty-five patients were considered to be "potential" donors (table), 22 from Nottingham wards and 3 from the neurosurgical unit. The diagnoses were head injury 15 , subarachnoid haemorrhage 7 , post-cardiac arrest 2 , and overdose of drug 1 . Twenty-two of these 25 patients were on a ventilator at some stage in their illness.

table-Numbers, Age, and Sex of "Potential" Donors

\begin{tabular}{c|c|c}
\hline Age & Male & Female \\
\hline $11-20$ & 3 & 1 \\
$21-30$ & 5 & 2 \\
$31-40$ & 2 & 3 \\
$41-50$ & 1 & 1 \\
$51-60$ & 2 & 2 \\
$61-70$ & 1 & 2 \\
\hline Total & 14 & 11 \\
\hline
\end{tabular}

After following these patients through their hospital course the number of "potential" donors was reduced from 25 to 17 patients. The other 8 patients were transferred out of the intensive care units breathing spontaneously (though still unconscious), or became hypotensive, uraemic, or infected before death.

Twelve kidneys were removed ( 6 from intensive care patients and 6 from neurosurgical patients). Relatives' refusal accounted for the loss of 6 kidneys, and the doctors looking after the patients did not consider the possibility on 7 occasions (14 kidneys). On one occasion there was no relative available to ask, though kidney donation was considered. Only one patient carried a kidney transplant donor card. The total number of cadaveric kidneys available was therefore 34, of which 12 were obtained and used. This represents 43 kidneys per million of population per year.

\section{Discussion}

Irreversible kidney failure caused death until regular dialysis and renal transplantation became realistic and effective. These treatments now allow patients to lead a prolonged and useful life. The application of these techniques to all suitable patients, approximately 45 per million population per year under $65,{ }^{2}$ is restricted. Initially this was due to lack of skill in a developing field, but for the last six years economic factors have prevented adequate facilities being provided. An increase in renal transplantation is now a cheaper alternative to regular dialysis and preferred by most patients. The number of cadaveric kidney transplants taking place is, however, limited by a lack of donor kidneys.

This study indicates that there are enough kidneys potentially available for most patients to be treated with a transplant, apart from the need for retransplantation and the possibility of some live relative donors. The full co-operation of all doctors and relatives would be needed, as well as sufficient time, facilities, and staff to retrieve these kidneys. (The organization associated with a kidney donation takes around 4-6 hours of a doctor's time in addition to one hour of time in the operating theatre.)

In addition to the donors identified in this study there may have been more patients in the general wards who would have fulfilled the criteria for kidney donation, but experience suggests that these would have been very few. Patients dying after cardiac arrest are considered potential donors in some hospitals, but there are not enough staff or operating time available in most hospitals to cope with a totally unexpected death. The number of potential donors identified at the neurosurgical unit might have been greater if this part of the study had also been carried out prospectively, but this was not possible.

It is important to record the change in attitude of those doctors looking after patients on the intensive care wards during the period of this study. All doctors had been sent many reminders about kidney donation and instructions on what to do in the event of a potential donor coming under their care (a kidney retrieval team was on constant call), but only half the number of potential donors were considered in the first six months of the survey. In January 1974 the first kidney transplant operation in Nottingham was performed. It was associated with much local press and radio coverage as well as becoming a talking point in the local hospitals. Thereafter the doctors considered over $80 \%$ of the potential donors, and subsequent donor referral has remained high.

The problem that now seems most important is lack of relatives' consent to kidney donation. This has occurred in over $50 \%$ of the interviews at which relatives have been asked. This refusal was often associated with disbelief and surprise about being asked and a complete lack of knowledge of what was involved. The question was often put by the doctors looking after the patient rather than a member of the kidney retrieval team. We are doubtful whether this altered the outcome, as the lack of prior awareness seemed to be the major common factor in refusal. In addition there is the question of the stage of an illness at which the relatives are best asked. If the question is put too soon after admission, relatives may tend to say no, out of fear that they might prejudice the patient's interests. If the question is delayed, and death takes place suddenly, there may be no one available to ask. This problem could be resolved by a change in the law regarding donor organs.

If all potential kidneys are to be used there has to be a change of attitude of doctors and relatives. We have shown that the change in the attitude of doctors can take place over a short time, probably the result of local transplantation. This suggests that an increase in the number of transplant units would also increase the number of cadaveric kidneys. The local publicity surrounding kidney transplant operations may also influence the general public, so that they are more able to give consent to kidney donation taking place. We have not yet found this to be true in Nottingham, but it will probably occur over a longer period of time. To attempt to influence public opinion an exhibition about transplantation and dialysis was held in the centre of Nottingham at the end of the period of the survey.

Recently the British Medical fournal ${ }^{3}$ has suggested that economic conditions may create difficult priority decisions and used the example of a potential choice between continuing to care for patients with renal failure or for mentally handicapped children. It may be preferable to look at alternative methods of economizing. Replacing expensive regular dialysis treatment by renal transplantation, which costs little more than other forms of major surgery, would produce major financial savings and also provide the treatment that many patients prefer. Medical staff, and the communities in which they practise, have the power to hasten the change towards this policy.

This study was supported by a grant from the Trent Regional Authority. The authors would like to thank all the clinicians in the Nottingham and Derby hospitals for permission to review their patients' case notes.

\section{References}

1 Crosby, D. L., West, R. R., and Daviea, H., British Medical fournal, 1971,

${ }^{2}$ Dombey, S. L., Sagar, D., and Knapp, M. S., British Medical fournal, 1975, in press.

3 British Medical fournal, 1974, 4, 306. 